\title{
Enzymatically activated emulsions stabilized by interfacial nanofibre networks
}

Inês P. Moreira, ${ }^{1}$ Meghan Hughes, ${ }^{2}$ Ivan Ramos-Sasselli,,${ }^{1}$ Daniel A. Cannon, ${ }^{1}$ Tell Tuttle, ${ }^{1} *$ Rein

$$
\operatorname{Ulijn} n^{1,2,3 *}
$$

${ }^{1}$ WestCHEM, Department of Pure and Applied Chemistry, University of Strathclyde, 295 Cathedral St, Glasgow G1 1XL, U.K.

${ }^{2}$ Advanced Science Research Center (ASRC), City University of New York, 85 St Nicholas Terrace, New York NY10031, USA.

${ }^{3}$ Hunter College, 695 Park Avenue, New York, NY 10065, USA.

\section{Corresponding Author}

*To whom the correspondence should be addressed:

Dr. Tell Tuttle, email: Tell.Tuttle@strath.ac.uk

Prof. Dr. Rein V. Ulijn, email: Rein.Ulijn@asrc.cuny.edu

KEYWORDS: Nanostructures, Self-Assembly, Stimuli-responsive, Peptides, Enzymatic, Surfactants, Emulsions 


\section{ABSTRACT}

We report on the on-demand formation of emulsions stabilized by interfacial nanoscale networks by biocatalytic self-assembly of Fmoc (9-fluorenylmethoxycarbonyl) dipeptide amphiphiles in aqueous/organic mixtures. The use of an alkaline phosphatase to transform phosphorylated precursors into self-assembling aromatic peptide amphiphiles (Fmoc-tyrosine-leucine, Fmoc-YL) provides a route to trigger self-assembly of nanofibrous networks and gels. In biphasic organic/aqueous systems, these networks form preferentially at the interface. This gives rise to the possibility of on-demand activation of emulsifying ability, producing switchable emulsions that may be activated by enzyme addition, even after storage of the biphasic mixture for several weeks. Experimental (Fluorescence and FTIR spectroscopy) and computational techniques (Atomistic Molecular Dynamics) are combined to show that the self-assembly process of FmocYL occurs through aromatic interactions and hydrogen bonding to generate an interfacial nanofibrous network.

\section{INTRODUCTION}

Surfactants are commonly used within the cosmetics, food, coating and pharmaceutical industries to stabilize emulsions due to their ability to increase the interfacial area between two immiscible phases, avoiding their coalescence. ${ }^{1,2}$ Over the last decades, alternatives to common surfactants have been studied and developed. ${ }^{2}$ Many approaches have been developed, such as pickering emulsions based on solid particles, ${ }^{3-5}$ bolaamphiphiles, ${ }^{6}$ microcapsules, ${ }^{7,} 8$ and surfactant-like peptides, ${ }^{9}$ for water-in-oil, oil-in-water or even water-in-oil-in-water emulsions. ${ }^{10}$ In addition, so-called pepfactants (long chain (21-mer) peptide surfactants) have been demonstrated to stabilize foams and emulsions at fluid-fluid interfaces in a stimuli-responsive 
manner by changing the bulk solution conditions. ${ }^{11,12}$ The ability to activate emulsions ondemand would add control over formulation and processing of emulsions, which may have benefits to industrial applications, ${ }^{2,13}$ e.g. when using ingredients with limited shelf-lives or by facilitating mixing by preventing instantaneous stabilization. However, changes in $\mathrm{pH}$ or temperature are not an attractive switch for some industrial applications where conditions must be kept stable throughout the process.

Self-assembly of small molecules into organised and stable structures has been a topic of significant interest since this new approach to generating biomaterials was introduced. ${ }^{14}$ As one particularly versatile class of gelators, aromatic peptide amphiphiles, consisting of a short (di- or tri-) peptide sequence capped at the N-terminus with an aromatic hydrophobic functional group such as N-(fluorenyl-9-methoxycarbonyl) (Fmoc), have been studied extensively in relation to their ability to form self-supporting hydrogels. ${ }^{15-18}$ A number of chemical and physical means have been used as a trigger to initiate self-assembly and to influence the produced nanostructures. ${ }^{19-24}$ In particular, the biocatalytically triggered self-assembly of aromatic peptide amphiphiles enables control of the self-assembly process under constant and physiological conditions. ${ }^{25} \mathrm{Xu}$ et al. was the first to exploit enzymatic self-assembly of Fmoc-amino acid using an alkaline phosphatase to dephosphorylate Fmoc-tyrosine phosphate (Fmoc-Yp) under basic conditions, forming a hydrogel, ${ }^{26}$ but many more followed. ${ }^{27-31}$

Recently, we demonstrated that Fmoc- (and pyrene-) dipeptide amphiphiles, when in a biphasic system, can self-assemble into nanofibrous networks at the aqueous/organic interface, upon brief shaking by hand, resulting in the ability to stabilize emulsions. ${ }^{32}$ These emulsifiers undergo self-assembly based on non-covalent interactions. They were demonstrated to possess higher stability towards temperature and salts when compared to a commonly used surfactant 
(sodium dodecyl sulfate, SDS), which absorbs to the interface. However, whilst the ability of an emulsion to withstand a range of environmental conditions is attractive, it is beneficial to have control over the (de)formation process (i.e. triggered emulsification). Therefore, we investigated the possibility of combining the advantages of aromatic peptide amphiphiles network formation at interfaces (stability) with enzymatic self-assembly to enable the control of the on-demand stabilization/destabilization of emulsions. In particular, we describe the phosphatase-mediated conversion of a phosphorylated peptide amphiphile with modest emulsion stabilization capability to the corresponding dephosphorylated gelator, which forms a stable, permanent interfacial network (Figure 1).

Some alkaline phosphatases are membrane-bound and integral membrane proteins (others are secreted into the cytosol), demonstrating that they are able to operate at interfaces. ${ }^{33}$ More generally, many studies have shown the stability and activity of enzymes in non-aqueous (including biphasic) media. ${ }^{34,35,36}$ Perhaps surprisingly, we have not found any published work on the use of phosphatases in aqueous/non-aqueous biphasic media.

In addition to the main objective of achieving enzymatic activation of emulsions, we also aimed to achieve an understanding of the non-covalent interactions behind the self-assembled nanostructure formation, using a combined computation and experimental approach. 
(a)

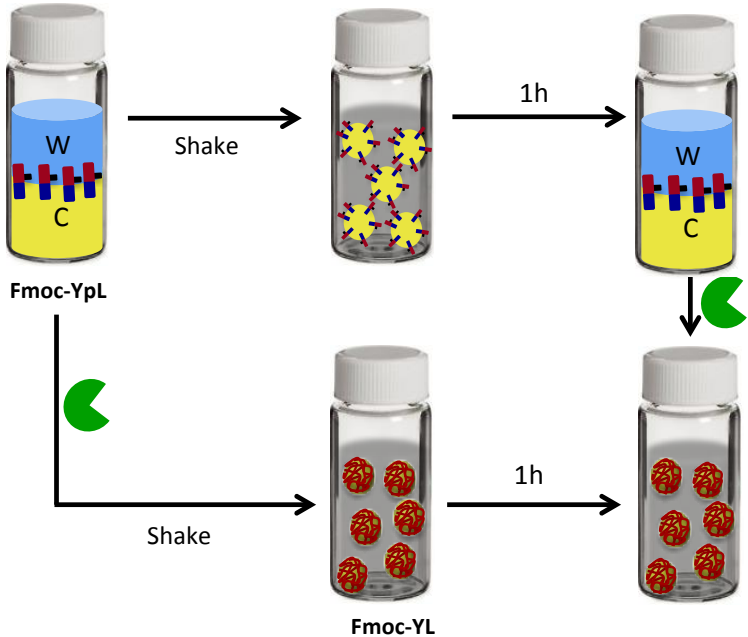

(b)

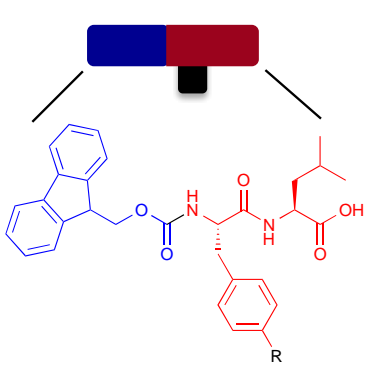

(c)

Fmoc-YpL: $\mathrm{R}=\left(\mathrm{PO}_{4}\right)^{3-}$

Fmoc-YL: $\quad \mathrm{R}=\mathrm{OH}$

Figure 1. (a) Schematic representation of the behaviour of Fmoc-YpL before and after alkaline phosphatase dephosphorylation in a chloroform/water biphasic system, showing the ability of Fmoc-YL to stabilize emulsions, contrary to Fmoc-YpL which follows a surfactant-type behavior and relaxes back to two-phases after 1 hour. Cyan blue represents water, yellow chloroform and green the alkaline phosphatase; (b) Cartoon and chemical structures of aromatic peptide amphiphiles Fmoc-YpL and Fmoc-YL; (c) Cartoon representing the enzyme and alkaline phosphatase structure (from Protein Data Bank).

The first part of this study details the enzymatic conversion, using alkaline phosphatase, of the precursor Fmoc-tyrosine phosphate-leucine (Fmoc-YpL, Figure 1b) into Fmoc-tyrosine-leucine (Fmoc-YL, Figure 1b) in aqueous buffer. The resulting hydrogel is experimentally characterised and the non-covalent interactions that dictate the nanostructure formation are analysed both experimentally and correlated with simulations. Having established the ability of the enzyme to trigger the self-assembly process, the second part of the study is to investigate the on-demand 
formation of amphiphile Fmoc-YL fibres at the chloroform/water interface, converting the surfactant-adsorbed biphasic mixture into a network-stabilized emulsion (Figure 1a).

\section{RESULTS AND DISCUSSION}

Enzymatic Conversion of Fmoc-YpL to Fmoc-YL. The precursor solution, $10 \mathrm{mM}$ Fmoc-YpL in $0.6 \mathrm{M}$ sodium phosphate buffer $\mathrm{pH} 8$, is not able to form a gel and does not show any evidence of fibre formation (Figure 2a or Figure S1a from ESI) due to electrostatic repulsion between deprotonated phosphate groups. Upon addition of alkaline phosphatase, the clear solution of the precursor Fmoc-YpL was converted into Fmoc-YL, producing a nanofibrous network (Figure 2b) that resulted in a hydrogel. Similar observations have been reported using Fmoc-Yp, ${ }^{26,37}$ Fmoc-Phenylalanine-Yp (Fmoc-FYp), ${ }^{18,}{ }^{27}$ Fmoc-FpY ${ }^{28}$ Fmoc-Yp-Serine (Fmoc-YpS) and Fmoc-Yp-Asparagine (Fmoc-YpN) ${ }^{29}$ Monitoring of the dephosphorylation reaction by reversed phase HPLC (Figure 2f) revealed that approximately 90\% of Fmoc-YpL is converted into FmocYL after 2 hours, with complete conversion to Fmoc-YL achieved within 24 hours (Figure 2f). 
(a)

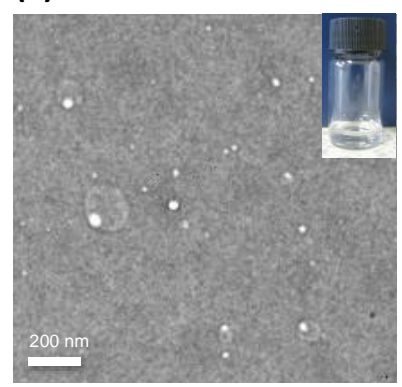

(c)

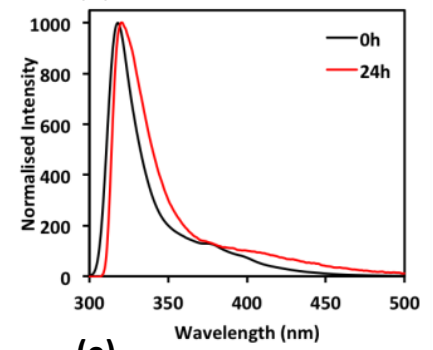

(e)

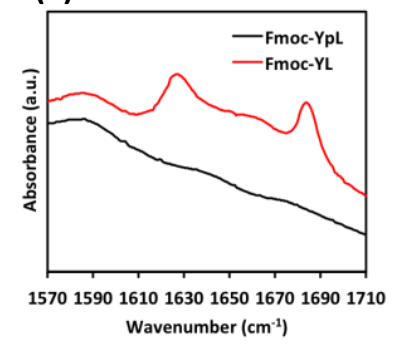

(b)

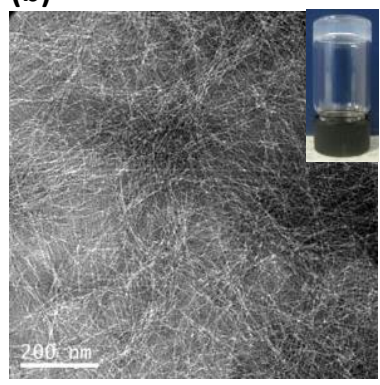

(d)

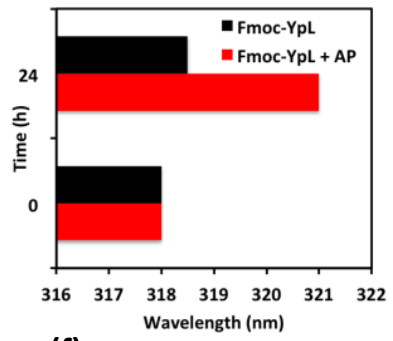

(f)

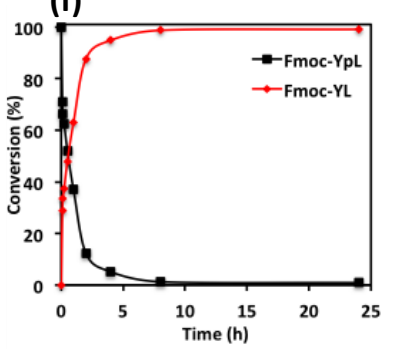

Figure 2. TEM image (Ammonium molybdate 2\% stain) (see also Figure S1 from ESI) and macroscopic appearance of Fmoc-YpL (a) and TEM image of Fmoc-YL (b), showing formation of nanofibrous network and self-supporting hydrogel (c) Normalised fluorescence emission spectra of Fmoc-YpL (0h) and Fmoc-YL achieved 24h after enzyme addition (un-normalised data included in Figure S3 from ESI) (excitation $280 \mathrm{~nm}$ ); (d) Representation of the lambda max wavelength at which fluorenyl peaks were observed before and 24 hours after enzyme addition, showing a red-shift (except for the Fmoc-YpL control); (e) Amide region of FTIR absorbance of Fmoc-YpL and Fmoc-YL; (f) Dephosphorylation from Fmoc-YpL to Fmoc-YL monitored by reversed phase HPLC.

The self-assembly process of aromatic peptide amphiphiles is known to be controlled by weak non-covalent hydrophobic interactions such as $\pi-\pi$ stacking between fluorenyl groups and hydrogen bonding between amino acids. ${ }^{20,21,38}$ Fluorescence spectroscopy spectra can provide evidence of aromatic interactions, since these may stabilize and form excimers which emit at 
lower energy and cause shifts to higher wavelengths (resulting in red-shifted emission spectra) ${ }^{20}$ When comparing the normalised emission curves (Figure 2c), it is possible to observe a red-shift on the fluorenyl peak (approximately $320 \mathrm{~nm}$ ) after dephosphorylation and gelation, in agreement to what has been reported for Fmoc-Yp ${ }^{37}$ and Fmoc-FpY. ${ }^{27}$ The emergence of this red-shift over time is represented in Figure 2d. The time-course for the lambda max wavelength of Fmoc-YL produced upon the addition of alkaline phosphatase in Figure S3 of the ESI. The initial blue-shift probably occurs due to the disruption of stacking interactions when phosphate groups start to be cleaved, followed by a red-shift that points to a gradually formed fluorenyl stacking arrangement that gives rise to fibres as previously observed for the dephosphorylation of Fmoc-Yp. ${ }^{39}$ The shoulder (peak at $375 \mathrm{~nm}$ ), associated to micellar aggregates, ${ }^{28,39,40}$ is only visible before the addition of alkaline phosphatase, which supports a micelle to fibre transition, by rearranging of the peptide chains and aromatic moieties upon dephosphorylation.

Fourier transform infrared (FTIR) absorbance can be used to analyse the H-bonding environment of the self-assembled peptide structure. ${ }^{20}$ A comparison of the peaks in the amide I region of the spectra (Figure 2e) indicate the nature of H-bonding interactions for the carbonyl moieties in both the precursor Fmoc-YpL and the hydrogelator Fmoc-YL. The prominent band for Fmoc-YL at $\sim 1625 \mathrm{~cm}^{-1}$ is indicative of a $\beta$-sheet-like arrangement of the monomers, while the intensity of the band at $\sim 1680 \mathrm{~cm}^{-1}$ is related to the formation of H-bonds with the carbonyl group of the carbamate moiety in Fmoc. ${ }^{41}$ The absence of these peaks in the precursor solution confirms that there is no such persistent H-bonded structure present in Fmoc-YpL. However, the addition of alkaline phosphatase results in the conversion of Fmoc-YpL to Fmoc-YL and a $\beta$ sheet-like H-bonding structure is formed (Figure 2e). For both Fmoc-YpL and Fmoc-YL the 
FTIR spectra reveal a broad peak at approximately $1580 \mathrm{~cm}^{-1}$, which indicates a deprotonated fraction of terminal carboxylates. ${ }^{41}$

The formation of stable, persistent, intermolecular interactions is critical for the transition from micellar aggregates, observed for Fmoc-YpL, and nanostructures formed by Fmoc-YL. In order to gain further insight into the difference in supramolecular interactions upon dephosphorylation, we performed molecular dynamics simulations of the aqueous systems, with an initial random arrangement of 60 molecules of either Fmoc-YpL or Fmoc-YL. Snapshots taken from the completion of the $200 \mathrm{~ns}$ simulation reveal that after this time the 60 molecules of Fmoc-YpL form an aggregate (Figure 3a), with a clustering of the fluorenyl groups and solvent exposure of phosphate groups, whereas the simulation of Fmoc-YL results in the formation of a more extended, fibre-like structure (Figure 3b) after $200 \mathrm{~ns}$. In addition to the qualitative data provided by the final snapshots, the analysis of the H-bonding networks between the residues in the simulation was performed. The first $50 \mathrm{~ns}$ of the simulation involve the aggregation of the monomers and the formation of H-bond networks for both systems (Figure $3 \mathrm{c}$ and $3 \mathrm{~d}$ ). However, after 50 ns the H-bonding networks show distinctly different characteristics. 

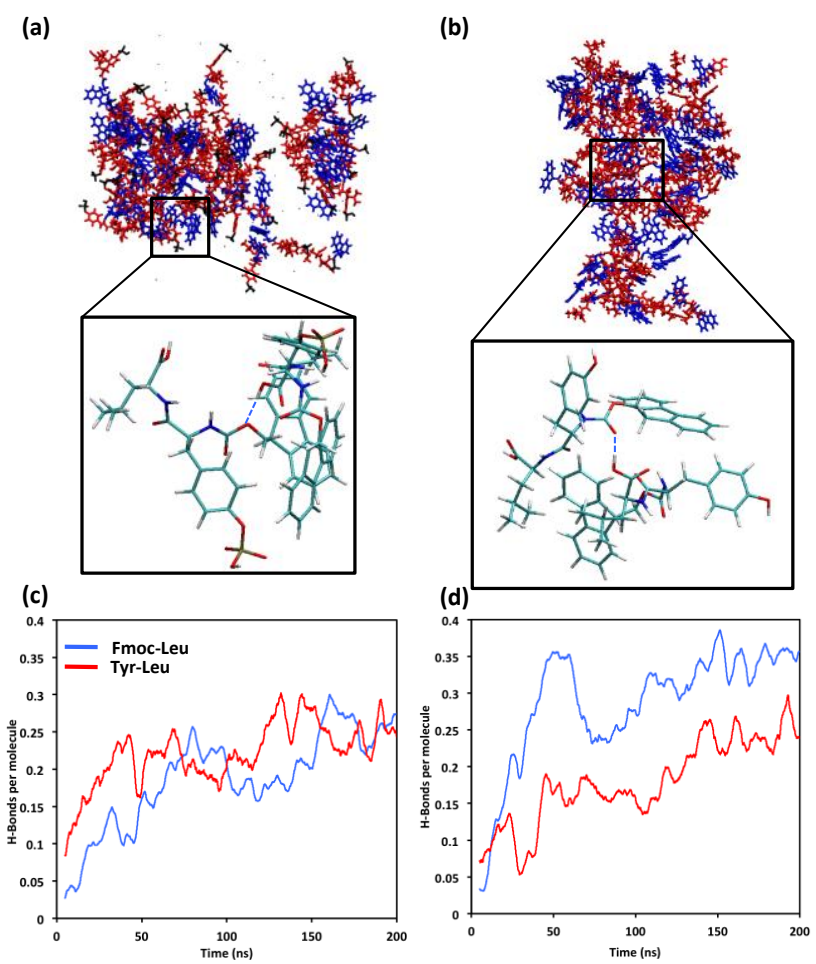

Figure 3. (a) Snapshot of the system of Fmoc-YpL after 200 ns. Fmoc is represented in blue, Tyrosine and Leucine in red, phosphate group in black and ions in grey. Inset presents one Fmoc-Leu H-bonding (between ester oxygen in carbamate group and terminal leucine $\mathrm{OH}$ ) between 2 molecules, and the Fmoc group clustering, coloured by atom type; (b) Snapshot of the system of Fmoc-YL after 200 ns. Fmoc is represented in blue, Tyrosine and Leucine in red. Inset presents Fmoc-Leu (between carboxyl oxygen on the Fmoc carbamate and terminal leucine $\mathrm{OH}$ ) between 2 molecules, coloured by atom type; (c) Hydrogen bonds between Fmoc and Leu residues (blue line) and Tyr and Leu residues (red line) per Fmoc-YpL molecule throughout the simulation; (d) Hydrogen bonds between Fmoc and Leu residues (blue line) and Tyr and Leu residues (red line) per Fmoc-YL molecule throughout the simulation. For all hydrogen bond interaction profiles see the ESI Figure S4.

The MD simulation of Fmoc-YpL shows no persistent H-bonds forming between the residues of the monomers of Fmoc-YpL (Figure 3c). There is a slight preference for the formation of $\mathrm{H}-$ bonds between the Fmoc and Leu residues of monomers and between the Tyr and Leu residues. However, the relative ordering of these interactions changes throughout the lifetime of the simulation (visible in Figure S4a from ESI, where all the interactions are presented). This 
variability in the H-bond network is indicative of a lack of structure in the aggregate and within the final snapshot of the simulation the only H-bond interactions between Fmoc and Leu involved the ester group of the carabamate and the protonated C-terminus of Leu (Figure 3a). In contrast, the MD simulation of Fmoc-YL shows a clear preference for the formation of FmocLeu H-bonds, followed by the persistent formation of Tyr-Leu H-bonds (Figure 3d), when comparing all the inter-residue H-bonds (see Figure S4b in the ESI). These trends suggest that a final stabilized fibre-like structure is being formed for Fmoc-YL (Figure 3b). The stability of the Fmoc-Leu interaction is consistent with the FTIR band at $\sim 1680 \mathrm{~cm}^{-1}$ (which is consistent with the H-bonding of the carbonyl group in the carbamate of Fmoc. Moreover, the Tyr-Leu backbone H-bonding interactions are also present throughout the simulation, which is consistent with the $\sim 1625 \mathrm{~cm}^{-1}$ band in the FTIR.

Enzymatically Triggered Emulsions. When chloroform is added in a 1:1 volume ratio to the 5 $\mathrm{mM}$ Fmoc-YpL buffer solution and hand-shaken for 5 seconds, an emulsion is formed due to its surfactant like behavior, where the amphiphile absorbs to the oil/water interface. However, Fmoc-YpL is unable to effectively stabilize the interface and de-emulsification occurs after one hour (Figure 4a). On the other hand, when alkaline phosphatase is added to the biphasic system containing Fmoc-YpL and hand-shaken, an emulsion is created that is stable for months, indicating rapid enzymatic conversion and subsequent formation of nanostructures of Fmoc-YL that are self-assembled at the interface between water and chloroform (Figure 4a), as demonstrated previously. ${ }^{32}$ Enzymatic activation of emulsions allows temporal control over emulsification, achieved by adding alkaline phosphatase to the Fmoc-YpL biphasic system (Figure 4a). 
(a)

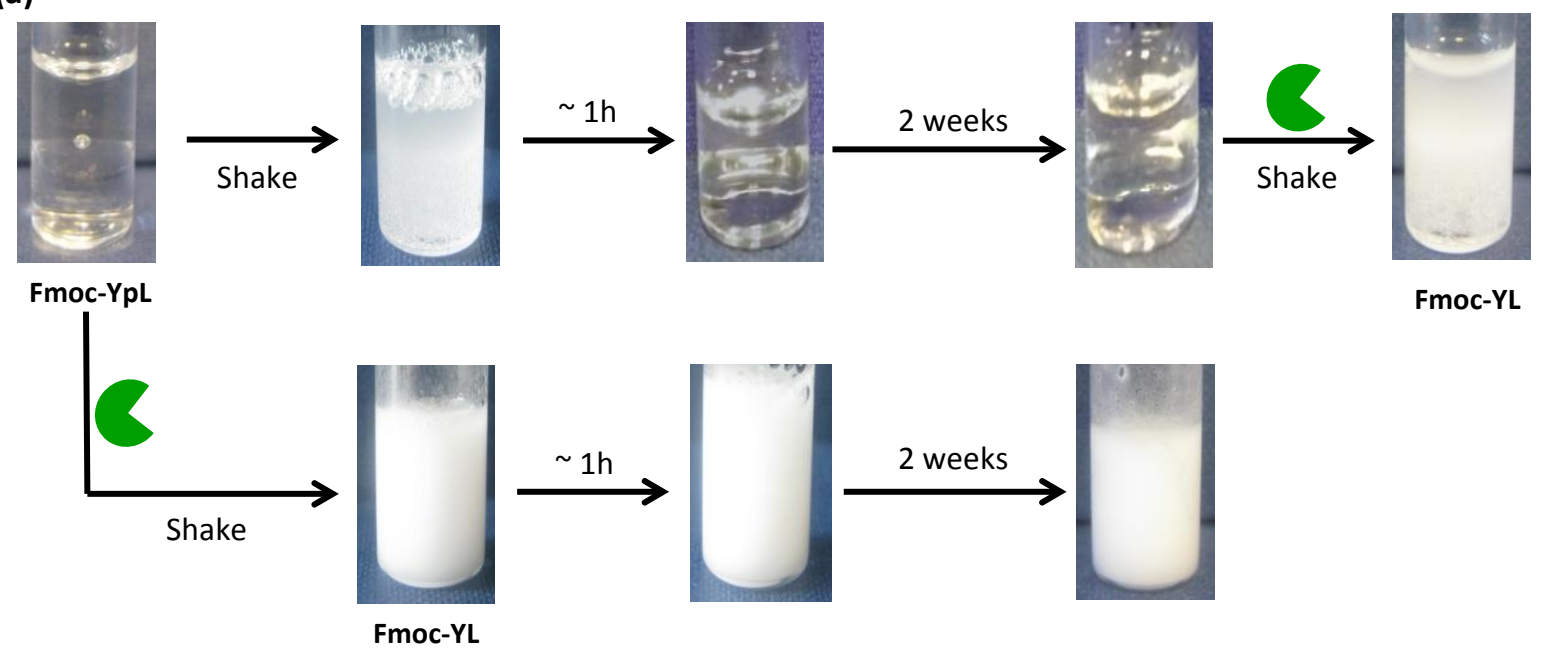

(b)

(c)

(d)
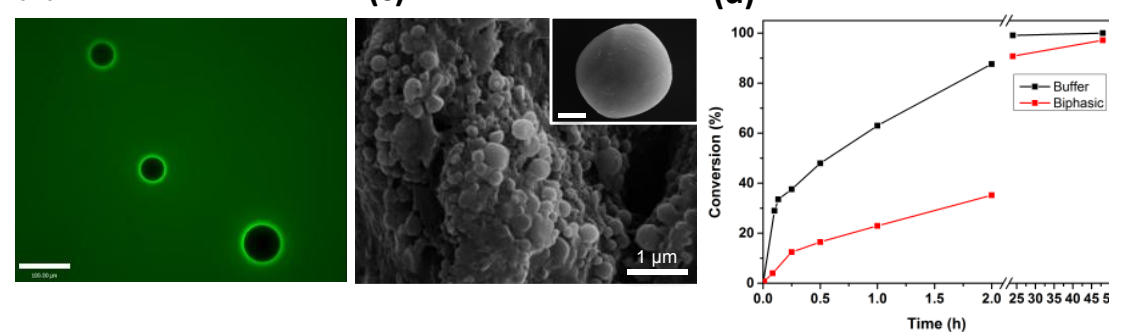

(e)

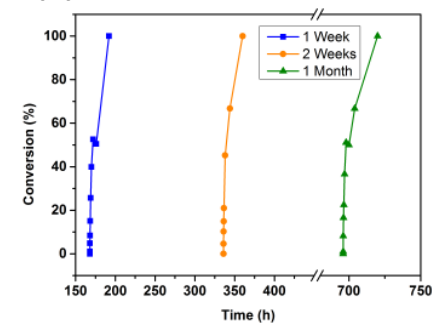

Figure 4. a) Optical photographs of glass vials showing the macroscopic appearance of FmocYpL and Fmoc-YL in a chloroform/water biphasic system, immediately after hand shaking for 5 seconds and after 1 hour/2 weeks, in addition to the ability of Fmoc-YpL, completely demulsified after 2 weeks, to form an emulsion when alkaline phosphatase is added; (b) Fluorescence microscopy image of chloroform-in-water emulsion stabilized by nanofibrous networks of Fmoc-YL containing FITC in water phase. Scale bar is $100 \mu \mathrm{m}$; (c) SEM image of chloroform-in-water emulsion droplet. Scale bar is $1 \mu \mathrm{m}$. Inset presents a zoomed-in chloroformin-water droplet. Scale bar is $10 \mu \mathrm{m}$; (d) Dephosphorylation monitored by reversed phase HPLC in buffer and in the biphasic system, showing that alkaline phosphatase is active in the chloroform/water system; (e) Dephosphorylation monitored by reversed phase HPLC when adding alkaline phosphatase to the demulsified Fmoc-YpL at different timings.

We investigated the structure of the chloroform-in-water droplets stabilized by networks of Fmoc-YL nanofibres, using microscopy and spectroscopy methods. The fluorescence microscopy image when using FITC to label the water phase (Figure 4c) shows that chloroformin-water emulsions are formed and that Fmoc-YL is at the interface stabilizing the emulsion. 
Upon air-drying condition, it was possible to observe by SEM one of the Fmoc-YL stabilized chloroform-in-water droplets (Figure 4c), and the droplets in the environment are visible in Figure S3 in ESI. The activity of the alkaline phosphatase enzyme in the biphasic system was verified by the full conversion from Fmoc-YpL into Fmoc-YL when in a chloroform-water system, along with the water system (Figure 4d), even though a slower dephosphorylation rate in a biphasic system was observed. The on-demand activation, when alkaline phosphatase was added to biphasic Fmoc-Yp mixtures, was shown with similar conversion rates at 1 week, 2 weeks and 1 month after the chloroform-in-water emulsion has been prepared (Figure 4e).

The tendency of both aromatic peptide amphiphiles (Fmoc-YpL and Fmoc-YL) to transfer into chloroform, remain in water or absorb at the interface was investigated by UV-Vis spectra, measuring the absorbance in each phase (Figure 5a and Figure 5b). 31\% of Fmoc-YpL remains in the aqueous phase (Table 1), while for Fmoc-YL 14\% is still in water, with the remainder transferred to the interface. From these results, we can conclude that both amphiphiles tend to the chloroform/water interface. However, Fmoc-YL is able to remain at the interface to a greater extent as nanofibrous networks are formed at the interface (Figure 4c).
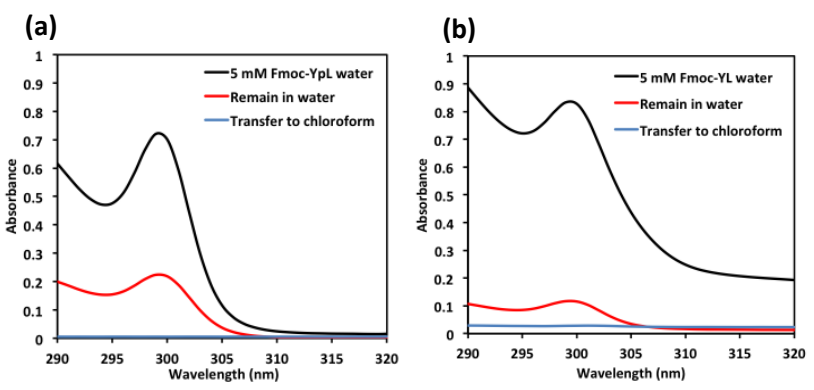

Figure 5. (a) Absorption spectra of Fmoc-YpL in $5 \mathrm{mM}$ buffer solution, amount remained in buffer and transferred to chloroform after emulsification; (b) Absorption spectra of Fmoc-YL in $5 \mathrm{mM}$ buffer solution, remained in buffer and transferred to chloroform after emulsification. 
Table 1. Partitioning of peptides (Fmoc-YpL and Fmoc-YL) between water, chloroform and that remains at the water/chloroform interface, along with $\log \mathrm{P}$ values of each calculated in ChemDraw version 14.0 from PerkinElmer.

\begin{tabular}{lcccc}
\hline & $\begin{array}{c}\text { Remain in } \\
\text { water }(\boldsymbol{\%})\end{array}$ & $\begin{array}{c}\text { Transfered } \\
\text { to } \\
\text { chloroform } \\
(\boldsymbol{\%})\end{array}$ & $\begin{array}{c}\text { Transfered } \\
\text { to the } \\
\text { interface } \\
(\%)\end{array}$ & LogP \\
\hline Fmoc-YpL & 31.03 & 0.74 & 68.23 & 5.67 \\
Fmoc-YL & 14.01 & 3.45 & 82.53 & 4.73 \\
\hline
\end{tabular}

MD simulations were carried out to investigate the ability of Fmoc-YpL and Fmoc-YL to form ordered structures in a biphasic environment. The 60 molecules of Fmoc-YpL or Fmoc-YL were randomly distributed in the water phase of a large box, which contained a TIP3P water and octanol $[1: 1$ ratio]. The tendency of both Fmoc-YpL and Fmoc-YL to aggregate towards the interface of the solvents was observed in the simulations (see final snapshots of the $200 \mathrm{~ns}$ simulation in Figure 6a and 6b). From the final snapshots of the system it is clear that although both systems are able to assemble at the interface of the solvents, Fmoc-YpL is evenly distributed along the length of the box, with minimal penetration into the octanol solvent, occurring predominantly for the Fmoc residues and the Leu residues (Figure 6a). In contrast, Fmoc-YL is able to form a more ordered aggregate which allows partitioning of the resulting fibre-like structure into the octanol phase (Figure 6b), which is qualitatively consistent with the results from partitioning experiments (Figure $5 \mathrm{~b}$ and Table 1). 

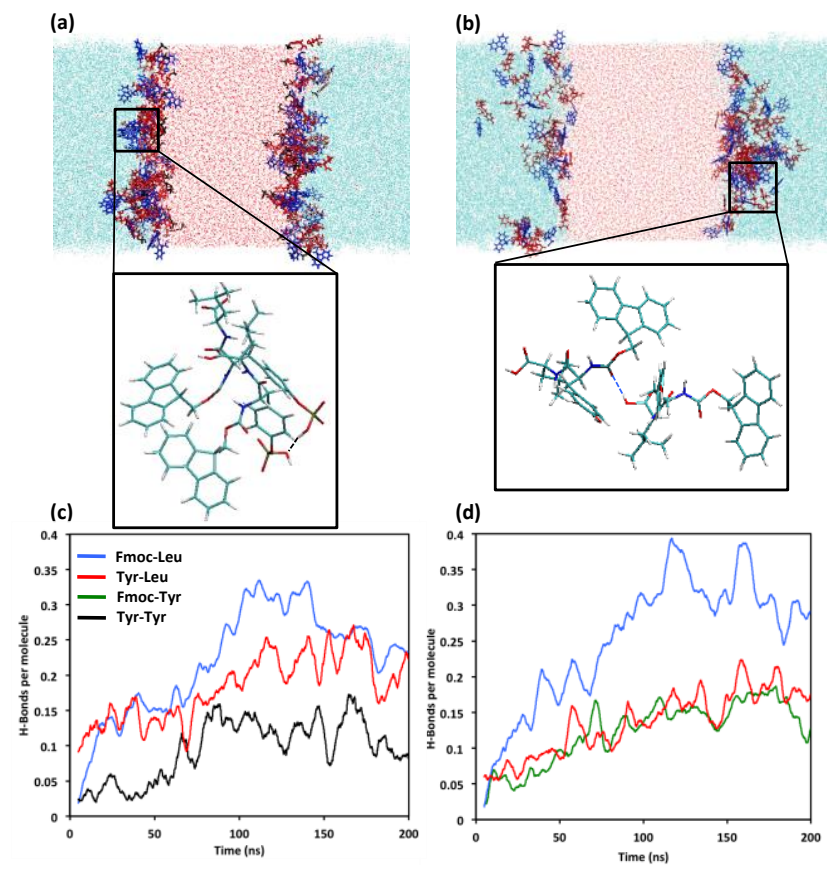

Figure 6. (a) Snapshot of Fmoc-YpL system after 200 ns. Fmoc is represented in blue, Tyrosine and Leucine in red, phosphate group in black, ions in grey, water in red and octanol in cyan. Inset presents one Tyr-Tyr H-bonding (between $\mathrm{OH}$ and $\mathrm{O}$ of the phosphate groups) between 2 molecules, coloured by atom type; (b) Snapshot of Fmoc-YL system after 200 ns. Fmoc is represented in blue, Tyrosine and Leucine in red, water in red and octanol in cyan. Inset presents Fmoc-Leu H-bond established between 2 molecules; c) Most prevalent hydrogen bonds per molecule between Fmoc-YpL molecules throughout the simulation in biphasic system; (d) Most prevalent hydrogen bonds per molecule between Fmoc-YL molecules throughout the simulation. For all hydrogen bond interaction profiles see the ESI Figure S5.

The formation of a nanostructure in the case of Fmoc-YL is again evident by the persistence of the Fmoc-Leu H-bonds and also Tyr-Leu and Fmoc-Tyr H-bonds to a lesser extent, observed during the lifetime of the MD simulation (Figure 6d and Figure S5b from ESI for the full H-bond profile). As was observed in the aqueous simulations, Fmoc-YpL has no strong preference and the H-bond network fluctuates, with H-bonds formed between the phosphate groups also playing an important role (visible in Figure S5a from ESI). The arrangement of Fmoc-YpL at the interface suggests a surfactant-type adsorption of the amphiphile at the interface, with the 
hydrophilic monomers facing the water and the hydrophobic the octanol. On the other hand, Fmoc-YL is able to form a nanofibrous network at the interface, which is consistent with the partitioning data (Table 1) and the ability of the dephosphorylated peptide to stabilize the oil-inwater emulsion over an extended period.

\section{CONCLUSIONS}

In this study we have demonstrated the possibility of using aromatic dipeptide amphiphiles to enzymatically activate nanofibre formation at organic/aqueous interfaces to stabilize chloroformin-water emulsions. We have demonstrated that Fmoc-YL is able to self-assemble in water following its enzymatic generation from the non-gelator precursor Fmoc-YpL. The selfassembled Fmoc-YL was shown to form nanofibres through non-covalent interactions, including $\pi$-stacking and H-bonding. When in a biphasic system, enzymatically-triggered Fmoc-YL selfassembles into nanofibrous networks at the chloroform/water interface, stabilizing the chloroform-in-water droplets and generating emulsions, which are stable for months. The stability of the emulsions and the possibility of "switching-on" the emulsifier ability by adding the enzyme at different time points provides a promising tool for mixing applications in chemical processes without the need to change conditions.

\section{MATERIALS AND METHODS}

All reagents were purchased at the highest purity available ( $\geq 98 \%)$ and used as supplied, unless stated otherwise. Fmoc-Tyr $\left(\mathrm{PO}\left(\mathrm{NMe}_{2}\right)_{2}-\mathrm{OH}\right.$ (537.55 g.mol $\left.{ }^{-1}\right)$ was purchased from Novabiochem. Fmoc-Tyr-OH (403.43 g.mol ${ }^{-1}$ ), L-Leucine tert-butyl hydrochloride (223.74

g.mol ${ }^{-1}$ ) and alkaline phosphatase from bovine, expressed in Pichia pastoris (5000 U.mg ${ }^{-1}$ protein, 
$20 \mathrm{mg}_{\text {protein. }} \cdot \mathrm{mL}^{-1}, 0.049 \mathrm{~mL}$, Apparent molar weight $160 \mathrm{kDa}$ ) were supplied by Sigma Aldrich. One enzyme unit corresponds to the quantity of alkaline phosphatase hydrolysing $1 \mu \mathrm{mol}$ of 4 nitrophenyl phosphate per minute at $\mathrm{pH} 9.8$ and $37^{\circ} \mathrm{C}$.

Gel Preparation. $10 \mathrm{mM}$ of synthesised Fmoc-YpL was prepared in $950 \mu \mathrm{L}$ of $0.6 \mathrm{M}$ sodium phosphate buffer $\mathrm{pH} 8$ and immediately added $50 \mu \mathrm{L}$ of alkaline phosphatase $\left(0.0555 \mathrm{U} . \mu \mathrm{L}^{-1}\right.$, or 55.53 U.mL ${ }^{-1}$ enzymatic concentration), vortexed and subject to ultra sounds at room temperature. All characterisation was done after 24 hours except when stated otherwise. For the Fmoc-YpL precursor, the preparation was the same except no enzyme was added.

Enzymatic reaction conversion by HPLC. To monitor the dephosphorylation by alkaline phosphatase, samples of $50 \mu \mathrm{L}$ were taken at different times since the addition of alkaline phosphatase $(\mathrm{t}=0 \mathrm{~h})$ and diluted in $500 \mu \mathrm{L}$ of $50 \%$ acetonitrile solution containing $0.1 \%$ TFA. $20 \mu \mathrm{L}$ of each sample was injected on a Dionex P680 system with a Macherrey-Nagel $250 \mathrm{~mm} \mathrm{x}$ 4.6 $\mathrm{mm} \mathrm{C18} \mathrm{column} \mathrm{for} \mathrm{reversed} \mathrm{phase} \mathrm{HPLC.} \mathrm{The} \mathrm{mobile} \mathrm{phase} \mathrm{comprised} \mathrm{of} \mathrm{water} \mathrm{and}$ acetonitrile at a flow rate of $1 \mathrm{~mL} \cdot \mathrm{min}^{-1}$. The gradient was linear to $20 \%(\mathrm{v} / \mathrm{v})$ acetonitrile in water at 4 minutes, gradually rising to $80 \%(\mathrm{v} / \mathrm{v})$ acetonitrile in water at 35 minutes and decreasing it to $20 \%$ acetonitrile in water at $42 \mathrm{~min}$. The intensity of the peptide peaks was analysed using a UVD170U UV-Vis detector at a $300 \mathrm{~nm}$ wavelength.

Fluorescence spectroscopy. Fluorescence emission spectra were recorded between 300 and $600 \mathrm{~nm}$ with an excitation light at wavelength $280 \mathrm{~nm}$ at medium response, $3 \mathrm{~nm}$ bandwidth and a $1 \mathrm{~nm}$ data pitch. Fluorescence emission spectra were measured on a Jasco FP-6500 spectrofluorometer with light measured orthogonally to the excitation light with a scanning speed of $500 \mathrm{~nm} \cdot \mathrm{min}^{-1}$. The samples were immediately placed in a UV cuvette and measured, with no dilution, at different times since the addition of alkaline phosphatase $(t=0 \mathrm{~h})$. 
Infrared Spectroscopy. FT-IR spectra were acquired using a Bruker Optics Vertex 70 spectrometer. Measurements were performed in a standard IR cell holder (Harrick Scientific), in which the sample was placed between two $\mathrm{CaF}_{2}$ windows separated by a $50 \mu \mathrm{m}$ PTFE spacer. Spectra for each sample were obtained by an average of 25 scans with a resolution of $1 \mathrm{~cm}^{-1} \cdot \mathrm{pH}$ $80.6 \mathrm{M}$ deuterated oxide phosphate buffer was used to prepare the samples.

Transmission Electron Microscopy. Carbon-coated nickel grids (300 mesh) were glow discharged in vacuum for 10-15 seconds. Then, the support films were touched onto the gel surface, blotted with filter paper and settled for 30 seconds. Ammonium molybdate $2 \%$ was used as a negative stain and the mixture blotted again for 30 seconds again. The samples were then dried for 10 minutes and imaged using a FEI TECNAI TEO microscope operating at $200 \mathrm{kV}$.

Emulsion Preparation. Fmoc-YpL was prepared in the same way as stated before but in a 5 $\mathrm{mM}$ concentration to avoid formation of hydrogels. After 24 hours from the Fmoc-YpL has been prepared in buffer and the alkaline phosphatase added (to assure full dephosphorylation), $500 \mu \mathrm{L}$ chloroform were added to $500 \mu \mathrm{L}$ samples and hand-shaken for 5 seconds to make a 50:50 chloroform-in-water emulsion.

UV-Visible Spectroscopy. Spectra were recorded between 250 and $400 \mathrm{~nm}$ on a Jasco UV-660 spectrophotometer. From the 50:50 chloroform-in-water emulsions, $20 \mu \mathrm{L}$ of the water or the chloroform layer were taken and diluted in $2 \mathrm{~mL}$ of water and chloroform, respectively, in a cuvette, and the absorbance measured. The percentage of the peptide remained in water, transferred to chloroform or to the interface was calculated having the peptide in water absorbance basis. $\log \mathrm{P}$ values for each compound were calculated in ChemDraw version 14.0 from PerkinElmer by following Crippen's method, ${ }^{42}$ Viswanadhan's fragmentation ${ }^{43}$ and Broto's method. ${ }^{44}$ 
Fluorescence Microscopy. The chloroform-in-water droplets were imaged on an Upright Epifluorescent Microscope (Nikon, Eclipse E600) by dropping the emulsion layer into a glass slide, covered with a coverslip and mounted. $1 \mathrm{mg} \cdot \mathrm{mL}^{-1}$ Fluorescein isothiocyanate (FITC) in 0.6 $\mathrm{M} \mathrm{pH} 8$ phosphate buffer was used to prepare the $5 \mathrm{mM}$ samples, to label the aqueous phase in the emulsion layers. The solutions were left overnight at room temperature (to make sure the full dephosphorylation by alkaline phosphatase was achieved) and, then, 50:50 chloroform-in-water emulsions prepared. Images were acquired using Zeiss x 20 or x10 dry objectives and the appropriate filter used (green for FITC).

Scanning Electron Microscopy. The emulsion phase was dropped into the double-sided carbon conductive tape and subject to air drying and under vacuum in an excicator. As soon as the samples were dry, they were sputter coated under vacuum in a Polaron SEM coating system SC515 with a gold/palladium target. The samples were then imaged using a JEOL6400 Scanning microscope at $10 \mathrm{kV}$.

On-demand activation test. To check if the system is switchable on-demand, besides an immediate addition of alkaline phosphatase to the 50:50 chloroform-in water Fmoc-YpL samples, the enzyme was added into the demulsified biphasic system of Fmoc-YpL 1 week, 2 weeks and 1 month after preparation. Photographs were taken and the dephosphorylation assessed by reversed phase HPLC.

\section{Computational}

Molecular Dynamic (MD) simulations were carried out in NAMD (NAnoscale Molecular

Dynamics) program ${ }^{45}$ using the CHARMM force field. ${ }^{46,47}$ Each system was minimised, at 300 $\mathrm{K}$, with the steep descent technique and then gradually heated up from 0 to $300 \mathrm{~K}$ for $55 \mathrm{ps}$ 
before being equilibrated for $445 \mathrm{ps,}$, to reach the system stabilization. Finally, the systems were run within an NPT ensemble at $1 \mathrm{~atm}$ and $300 \mathrm{~K}$ for $200 \mathrm{~ns}$. A 2.0 fs time step was used to integrate Newton's motion equation along with a $12 \AA$ cut-off for the non-bonded interactions. Periodic boundary conditions in the three-dimensional coordinates have been used.

Supporting Information. Synthesis of Fmoc-YL and Fmoc-YpL. Proposed intramolecular conformation of Fmoc-YL. This material is available free of charge via the Internet at http://pubs.acs.org."

\section{ACKNOWLEDGMENTS}

The authors gratefully acknowledge the financial support by the EC $7^{\text {th }}$ Framework Programme Marie Curie Actions via the European ITN SMARTNET No. 316656 and EMERgE/ERC No. 258775. They also want to thank Dr. Dimitrios Lamprou for assistance with AFM, Gillian Robb with epifluorescent microscope, Margaret Mullin from the University of Glasgow with TEM and SEM and the analytical facilities at the University of Strathclyde for the

NMR, Mass spectrometry and elemental analysis. Results were obtained using the EPSRC funded ARCHIE-WeSt High Performance Computer (www.archie-west.ac.uk; EPSRC grant no. $\mathrm{EP} / \mathrm{K} 000586 / 1)$.

\section{REFERENCES}

1. Holmberg, K.; Jönsson, B.; Kronberg, B.; Lindman, B. Journal of Synthetic Lu-brication 2004, 20, (4), 367-370. 
2. Liu, Y.; Jessop, P. G.; Cunningham, M.; Eckert, C. A.; Liotta, C. L. Science 2006, 313, (5789), 958-960.

3. Nesterenko, A.; Drelich, A.; Lu, H.; Clausse, D.; Pezron, I. Colloids and Surfaces A: Physicochemical and Engineering Aspects 2014, 457, 49-57.

4. Chevalier, Y.; Bolzinger, M.-A. Colloids and Surfaces A: Physicochemical and Engineering Aspects 2013, 439, 23-34.

5. Pickering, S. U. M. 1907.

6. Tang, C.; Qiu, F.; Zhao, X. Journal of Nanomaterials 2013, 2013, 15.

7. Antipov, A. A.; Sukhorukov, G. B.; Donath, E.; Möhwald, H. The Journal of Physical Chemistry B 2001, 105, (12), 2281-2284.

8. Morikawa, M. a.; Yoshihara, M.; Endo, T.; Kimizuka, N. Chemistry-A European Journal 2005, 11, (5), 1574-1578.

9. Zhao, X. Current Opinion in Colloid \& Interface Science 2009, 14, (5), 340-348.

10. Hanson, J. A.; Chang, C. B.; Graves, S. M.; Li, Z.; Mason, T. G.; Deming, T. J. Nature 2008, 455, (7209), 85-88.

11. Malcolm, A. S.; Dexter, A. F.; Middelberg, A. P. Asia-Pacific Journal of Chemical Engineering 2007, 2, (5), 362-367.

12. Malcolm, A. S.; Dexter, A. F.; Middelberg, A. P. Soft Matter 2006, 2, (12), 1057-1066.

13. Zhu, Y.; Jiang, J.; Cui, Z.; Binks, B. P. Soft Matter 2014, 10, (48), 9739-9745.

14. Vauthey, S.; Santoso, S.; Gong, H.; Watson, N.; Zhang, S. Proceedings of the National Academy of Sciences 2002, 99, (8), 5355-5360.

15. Vegners, R.; Shestakova, I.; Kalvinsh, I.; Ezzell, R. M.; Janmey, P. A. Journal of Peptide Science 1995, 1, (6), 371-378.

16. Yang, Z.; Gu, H.; Zhang, Y.; Wang, L.; Xu, B. Chemical communications 2004, (2), 208209.

17. Orbach, R.; Adler-Abramovich, L.; Zigerson, S.; Mironi-Harpaz, I.; Seliktar, D.; Gazit, E. Biomacromolecules 2009, 10, (9), 2646-2651.

18. Wang, W.; Chau, Y. Soft Matter 2009, 5, (24), 4893-4898.

19. Jayawarna, V.; Ali, M.; Jowitt, T. A.; Miller, A. F.; Saiani, A.; Gough, J. E.; Ulijn, R. V. Advanced Materials 2006, 18, (5), 611-614.

20. Fleming, S.; Ulijn, R. V. Chemical Society Reviews 2014.

21. Smith, A. M.; Williams, R. J.; Tang, C.; Coppo, P.; Collins, R. F.; Turner, M. L.; Saiani, A.; Ulijn, R. V. Advanced Materials 2008, 20, (1), 37-41.

22. Lin, Y.; Qiao, Y.; Tang, P.; Li, Z.; Huang, J. Soft Matter 2011, 7, (6), 2762-2769.

23. Tang, C.; Ulijn, R. V.; Saiani, A. Langmuir 2011, 27, (23), 14438-14449.

24. Adams, D. J.; Holtzmann, K.; Schneider, C.; Butler, M. F. Langmuir 2007, 23, (25), $12729-12736$. 
25. Yang, Z.; Xu, B. Journal of Materials Chemistry 2007, 17, (23), 2385-2393.

26. Yang, Z.; Gu, H.; Fu, D.; Gao, P.; Lam, J. K.; Xu, B. Advanced Materials 2004, 16, (16), 1440-1444.

27. Wang, W.; Yang, Z.; Patanavanich, S.; Xu, B.; Chau, Y. Soft Matter 2008, 4, (8), 16171620.

28. Sadownik, J. W.; Leckie, J.; Ulijn, R. V. Chemical Communications 2011, 47, (2), 728730.

29. Hughes, M.; Debnath, S.; Knapp, C. W.; Ulijn, R. V. Biomaterials Science 2013, 1, (11), 1138-1142.

30. Toledano, S.; Williams, R. J.; Jayawarna, V.; Ulijn, R. V. Journal of the American Chemical Society 2006, 128, (4), 1070-1071.

31. Hirst, A. R.; Roy, S.; Arora, M.; Das, A. K.; Hodson, N.; Murray, P.; Marshall, S.; Javid, N.; Sefcik, J.; Boekhoven, J.; van Esch, J. H.; Santabarbara, S.; Hunt, N. T.; Ulijn, R. V. Nature chemistry 2010, 2, (12), 1089-94.

32. Bai, S.; Pappas, C.; Debnath, S.; Frederix, P. W. J. M.; Leckie, J.; Fleming, S.; Ulijn, R. V. ACS Nano 2014, 8, (7), 7005-7013.

33. Klionsky, D. J.; Emr, S. D. The EMBO Journal 1989, 8, (8), 2241.

34. Klibanov, A. M. Nature 2001, 409, (6817), 241-246.

35. Bell, G.; Halling, P. J.; Moore, B. D.; Partridge, J.; Rees, D. G. Trends in Biotechnology 1995, 13, (11), 468-473.

36. Laane, C.; Boeren, S.; Vos, K.; Veeger, C. Biotechnology and Bioengineering 1987, 30, (1), 81-87.

37. Thornton, K.; Smith, A.; Merry, C. R.; Ulijn, R. Biochemical society transactions 2009, $37,(4), 660$.

38. Chen, L.; Morris, K.; Laybourn, A.; Elias, D.; Hicks, M. R.; Rodger, A.; Serpell, L.; Adams, D. J. Langmuir 2009, 26, (7), 5232-5242.

39. Thornton, K.; Abul-Haija, Y. M.; Hodson, N.; Ulijn, R. V. Soft Matter 2013, 9, (39), 9430-9439.

40. Abul-Haija, Y. M.; Roy, S.; Frederix, P. W. J. M.; Javid, N.; Jayawarna, V.; Ulijn, R. V. Small 2014, 10, (5), 973-979.

41. Fleming, S.; Frederix, P. W. J. M.; Ramos Sasselli, I.; Hunt, N. T.; Ulijn, R. V.; Tuttle, T. Langmuir 2013, 29, (30), 9510-9515.

42. Wildman, S. A.; Crippen, G. M. Journal of chemical information and computer sciences 1999, 39, (5), 868-873.

43. Ghose, A. K.; Viswanadhan, V. N.; Wendoloski, J. J. The Journal of Physical Chemistry $A$ 1998, 102, (21), 3762-3772.

44. Broto, P.; Moreau, G.; Vandycke, C. European journal of medicinal chemistry 1984, 19, (1), 71-78. 
45. Phillips, J. C.; Braun, R.; Wang, W.; Gumbart, J.; Tajkhorshid, E.; Villa, E.; Chipot, C.; Skeel, R. D.; Kale, L.; Schulten, K. Journal of computational chemistry 2005, 26, (16), 17811802.

46. Brooks, B. R.; Brooks, C. L.; MacKerell, A. D.; Nilsson, L.; Petrella, R. J.; Roux, B.; Won, Y.; Archontis, G.; Bartels, C.; Boresch, S. Journal of computational chemistry 2009, 30, (10), 1545-1614.

47. Vanommeslaeghe, K.; Hatcher, E.; Acharya, C.; Kundu, S.; Zhong, S.; Shim, J.; Darian, E.; Guvench, O.; Lopes, P.; Vorobyov, I. Journal of computational chemistry 2010, 31, (4), 671-690.

Table of Contents:

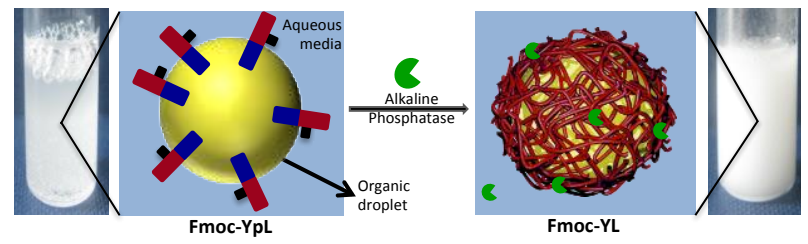

An innovative on-demand emulsifier is presented, based on the enzyme triggered self-assembly of aromatic dipeptide amphiphiles into fibre networks at aqueous/organic interfaces. 